RESEÑA

\title{
Naciones en campo: fútbol, identidades y nacionalismos en América Latina
}

Editores-compiladores: David Leonardo Quitián, Efraín Serna, Guillermo Humberto Montoya y Jorge Alejandro Villanueva (editores-compiladores). Entidades auspiciantes: Universidad Nacional Abierta y a Distancia-UNAD, Universidad de los Llanos, Universidad de Guanajuato, Instituto de Altos Estudios sobre Deporte, Cultura y Sociedad de México. Editorial: Kinesis, Colección Sociología y Deporte. Ciudad y año: Armenia, 2014.

\section{Andrés Dávila Ladrón de Guevara' Universidad Javeriana, Colombia.}

Los cuatro mosqueteros que figuran como editores-compiladores de Naciones en campo le entregan a las ciencias sociales latinoamericanas un excelente trabajo de aproximación al fútbol, al mundial de fútbol y a los seleccionados nacionales que lo juegan cada cuatro años. En efecto, sus casi 300 páginas recogen, en una mirada comprensiva y enriquecedora, los trabajos de muy diversos académicos que, en los últimos veinte años, se han aproximado desde distintas ópticas a ese fenómeno social omnipresente en el mundo desde finales del siglo pasado. Con un mérito adicional, que ha visto la luz prácticamente en simultánea con el desarrollo del Mundial de Brasil 2014, el cual dejó toda una gama de fenómenos adicionales que ameritan la preparación de una nueva publicación en los próximos meses.

Sinmás rodeos, valelapenapresentarlaestructura general del libro. Consta de un componente inicial en el cual están los agradecimientos, el prólogo, la nota de los editores y la introducción. Luego, en nueve capítulos recorre la producción de la mayoría de los países de América Latina, cuyos seleccionados fueron protagonistas del Mundial 2014, con excepción de Honduras e incluyendo a Venezuela, que no clasificó, pero que junto con la revolución bolivariana también se ha vuelto futbolera. Para comenzar y luego de los sentidos agradecimientos, el libro arranca con el prólogo escrito por Gabriel Restrepo, de la Universidad Nacional de Colombia y de la Asociación Colombiana de Investigación y Estudios sobre el Deporte. A la manera de un portero que organiza su defensa y da inicio al juego desde el saque de meta, Gabriel define desde allí el estilo predominante en el libro: la aproximación desde alguna de las ciencias sociales y desde distintas lecturas de lo social para dar cabida al fenómeno futbolero en toda su cabal y cambiante complejidad. En términos futboleros, Gabriel no revienta el balón, sino que sale jugando con sus defensas: escribe críticamente, pero desde la óptica de alguien que ha jugado, es hincha y gusta del fútbol. Todo lo cual no le impide mirarlo, desmenuzarlo, tal y como lo hace en esas páginas iniciales en las cuáles señala que "nada tan elusivo como la identidad de esa realidad irreal del fútbol (pág. 11)". Y por ello, esas páginas nos dan las primeras pistas para ir "más allá de los fetiches del fútbol". Gabriel da unos primeros pases fundamentales, no solo al destacar el carácter evanescente, virtual, del juego, sino al señalar la tensión real-virtual de las identidades hoy, y más si se procesan por intermedio del fútbol. Y en ellas los ladinoamericanos parecieran tener unos rasgos, unos procesos y unas dinámicas que es necesario conjugar adecuadamente con el fenómeno del fútbol hoy. Todo lo cual obliga, sin lugar a dudas, a repensar y replantear las preguntas y los abordajes sobre la identidad nacional y el fútbol.

En la Nota de los Editores, la línea de cuatro zagueros hace los señalamientos clave. El libro recoge, primordialmente, el trabajo colectivo que dinamizó la celebración del "Seminario Internacional de fútbol: identidades,

1 Politólogo, maestro y doctor en Ciencias Sociales de la Flacso, México. Actualmente es Profesor Asociado de la Facultad de Ciencias Políticas y Relaciones Internacionales de la Pontificia Universidad Javeriana de Bogotá, en donde es Director del Departamento de Ciencia Política. 
nacionalismo y fútbol", que se realizó en Bogotá y Villavicencio en enero de 2013. Y conduce a una novedosa y llamativa mezcla de lo que ellos denominan académicos consagrados, junto con jóvenes investigadores. Ello da cuenta de un campo de estudio en gestación y consolidación, el de los estudios socioculturales del deporte en América Latina. Allí sabemos que participan en la obra 32 autores para 30 textos, que por cantidades Colombia publica ocho, Brasil y México 6. Y que decidieron, de manera generosa y útil, reeditar tres textos.

Y en la introducción David, como todo un mariscal del área, establece las directrices del juego: "el fútbol como metonimia de la patria y la nación como fantasía futbolera consensuada" (pág. 19). Por ello, se busca en la épica narrativa propia de este deporte, más que de otros, esas afinidades con discursos políticos sobre una nación a la que se pertenece. En una rápida, breve y concisa referencia a la producción previa de mayor significación en las ciencias sociales pero, especialmente, en las de varios países de América Latina, se reafirman aquellos mecanismos, la radio por ejemplo, y aquellas instancias, los clubes y la selección, propicias para generar referentes de lo nacional. Con un llamado de atención sobre el papel que la publicidad juega en todo esto, sin que haya sido objeto aun de una mirada analítica o crítica.

Con las naciones en campo, comienza el recorrido por los distintos países sobre los cuales se recoge una rica producción en la materia. Cada capítulo corresponde a un país y se titula con alguna referencia discursiva que haya tenido reconocimiento nacional e internacional. En el primer capítulo se reedita el texto de Sergio Villena sobre "los usos nacionalistas del fútbol en Costa Rica". Con el rigor, la agudeza y, claramente, la distancia de no ser costarricense, Sergio recorre la temática a partir de dos importantes experiencias: la gloriosa y sorprendente de Italia 90 y la del retorno a la cita mundialista en CoreaJapón 2002. Además de un recuento histórico sencillo pero muy diciente de las claves de lectura sobre lo nacional, en particular por su conversión en una tradición nacional tica en la tensión entre lo campesino rural sencillo y lo urbano moderno, hay una sugerente mirada sobre las dos experiencias mundialistas. No sobra decir que la relectura del texto abre de inmediato la inquietud por la necesaria complementación del ejercicio, teniendo en cuenta la experiencia de Alemania 2006 y, sin lugar a dudas, la sorprendente, meritoria y reconocida gesta del 2014 eliminando a dos campeones mundiales y llegando a cuartos de final para ser derrotada únicamente en los tiros desde el punto penal.

El recorrido sigue por México con un conjunto interesante de artículos que mezclan distintas miradas. El de Andrés Fábregas Puig sobre la selección mexicana inicia también con un recorrido histórico donde se plantean algunas claves de lectura del caso mexicano; para luego dirigir su mirada a los clubes mexicanos y la construcción de tensiones y significaciones sociales y políticas diversas; cerrando luego el análisis con una referencia a la selección mexicana vista en clave de un país posible. Curiosamente, dado que México es un habitual participante de las citas mundialistas, hay más continuidades y constantes, entre ellas la de una especie de karma futbolero que les impide con uno $u$ otro equipo y uno $u$ otro técnico superar los octavos de final. En las reflexiones finales llama la atención la mirada compleja a la tensión entre lo nacional y lo futbolero, junto con la dinámica de espectáculo de masas y grandes cifras, producto de los negocios y mercadeo que caracteriza hoy al fútbol mundial. E, igualmente, al reconocimiento de cómo la selección es un símbolo que recoge, canaliza, viabiliza múltiples mexicanidades propias de "un país pluricultural pero desigual socialmente hablando" (pág. 54).

Jesús Galindo Cáceres accede al tema por otra vía: la de la "ingeniería en comunicación social del nacionalismo mexicano" con el caso de la selección nacional. El texto parte de las definiciones básicas sobre nación y nacionalismo, para desplegar luego el planteamiento fuerte sobre cómo la ingeniería en comunicación social del nacionalismo encuentra en el seleccionado 
de fútbol un lugar particularmente rico y potente para la construcción de referentes de nación: unos por la vía de las confrontaciones que genera el juego, otros por la vía del negocio. Destaca el autor que ello se hace por varios caminos: la cultural, la política y, como novedad, la de la mercadotecnia. Aún más, al continuar el ejercicio se reconocen dos nacionalismos: el político y el de mercado y se examina cómo opera ello en el caso de la selección nacional. Más que conclusiones, quedan preguntas sobre la causalidad dominante en el proceso y la pertinencia y oportunidad de seguirlo estudiando.

César Federico Macías, al modo de un carrilero izquierdo, enfoca su análisis en un caso particular: el del fútbol en Guanajuato. Desde una mirada histórica, se trata de recomponer la llegada del fútbol y su apropiación con distintos significados en la primera mitad del siglo XX. Se suman, así, argumentos que hunden sus raíces en procesos de configuración de las sociedades, mezclados con las dinámicas de los deportes y del fútbol en particular. En el caso de este texto, se argumenta centralmente hacia la configuración del fútbol como negocio, vía su profesionalización. No obstante, desde la mirada externa resulta llamativo prestar atención a procesos que a veces se piensan homogéneos y que mirados en detalle ofrecen una riqueza de procesos que están allí abiertos para ser estudiados.

Roger Magazine, Sergio Varela Hernández y Miguel Ángel González Ponce de León adelantan un ejercicio sencillo de encuesta a universitarios sobre sus percepciones e imaginarios en torno a la selección nacional que los representó en 2010 en Sudáfrica, bajo la idea de que hay un "dilema de la nación poscolonial". Si bien el texto cumple con los cometidos de un ejercicio académico y de investigación, que quedan plasmados en su desarrollo, presenta ante todo unos resultados interesantes que dan lugar a varios análisis y conclusiones. Encuentran, de manera interesante, nexos entre las ideas predominantes sobre el ser mexicano, lo que la selección representa y podría llegar a representar y lo que, en concreto, los jugadores llegan a significar. Aparecen también imágenes que no resultan tan diferentes a las que se expresan en otros países, especialmente cuando el problema es no conseguir los resultados o ser incapaces de evitar la derrota.

Finalmente, José Samuel Martínez López se centra en una figura icónica, el director técnico, por las expectativas, los retos y las cargas que se depositan sobre su espalda. Bajo la idea de que en el fútbol se sustituyen instituciones, liderazgos políticos y sociales y, claro está, referentes de nacionalidad, se hacen varios planteamientos interesantes para aproximarse al tema general y al que aquí se aborda en particular. Si bien se menciona al vasco Aguirre, entrenador en 2002 y 2010, la historia de esta posición en el caso mexicano daría para un rico análisis histórico, a cerrarse por ahora con la llamativa figura y personalidad del "Colorado" Herrera, quien milagrosamente salvó la clasificación al Mundial de Brasil y condujo al equipo a un muy destacado desempeño que, de todas formas, no permitió superar la fase imposible.

El tercer capítulo está dedicado a Ecuador. Fernando Carrión retoma varios temas trabajados previamente para insistir en algo que ya parece común: "la dimensión política del fútbol: su fascinación y encanto". Es en realidad un ensayo de planteamientos globales sobre esas relaciones que de tan obvias, a veces olvidamos elaborarlas. Se mira al fútbol como un fenómeno global, una práctica social de identificación colectiva, como un sistema de relaciones y representaciones en el cual la política está íntimamente vinculada, bien como ideología, como militancia y como propaganda. Paradójicamente, se mira más la historia general del fútbol y aspectos asociados con los clubes, sin llegar de lleno a desglosar lo sucedido con la selección ecuatoriana de fútbol desde 2002 hasta hoy.

El cuarto capítulo se dedica a Venezuela que, si bien no clasificó, sí tuvo el mejor desempeño de eliminatoria alguna. Alessandro D'amico hace un interesante recuento de "la vinotinto". 
Y lo hace, como el título lo indica, desde las representaciones sociales y la identidad nacional en la psicología del deporte. Luego de una breve introducción histórica en que se hace patente el hecho de que Venezuela no tenía una particular adhesión por el fútbol, sino por el béisbol, se resalta lo sucedido en la última década larga que, coincidencialmente, ocurre al mismo tiempo que el proceso de la revolución bolivariana. Hecho un recuento breve sobre algunos estudios que han mirado el tema en la región, con mención explícita a los trabajos sobre Bolivia (país no incluido junto con Perú ni Paraguay en el libro), indica la metodología, que se basó en entrevistas a profundidad a estudiantes universitarios, futbolistas profesionales $y$ profesionales del fútbol que no son futbolistas. Dada la diversidad de la muestra, se encuentran aspectos interesantes en torno a si la identidad nacional se redefine o se afirma, aunque está en entredicho todavía el alcance del fútbol en tal sentido. Por ello, se concluye que en el ejercicio de recolección de información se reconoce la aparición de representaciones sociales de la Vinotinto y de la identidad nacional, pero como fenómenos independientes uno de otro. Obviamente y hacia futuro la cuestión sigue abierta.

En el quinto capítulo se presentan los trabajos sobre el caso chileno. Carlos Vergara Constela y Rodrigo Soto Lagos avanzan en la propuesta de una "sociología del fútbol chileno", para lo cual van a los antecedentes, plantean varias propuestas de análisis e investigación y señalan los subsecuentes desafíos. En la primera parte del trabajo, luego de introducir la temática, examinan el estado del arte en América Latina, de manera muy somera y con mucho peso de lo producido desde la Argentina. Pasan luego a un examen parecido del caso chileno, la cual incluye un recorrido por eventos de reciente realización en el ámbito académico chileno. Desde allí se hace una propuesta en gestación con un par de directrices: posicionar el fútbol como un tema legítimo para la sociología, en tanto constituye una ventana para mirar lo social (pág. 120); y como un potencial campo de estudio, en tanto campo de luchas sociales, siguiendo la noción propuesta por Bourdieau. De allí derivan cuatro líneas de investigación que tienden a coincidir con las temáticas estudiadas a lo largo del libro, aunque proponen abordajes interesantes a la relación violencia, fútbol y sociedad, nueva estructura organizacional del fútbol profesional chileno y fútbol y ciudad.

Se insiste, de manera importante, en que los estudios sobre el deporte en Chile están apenas en gestación y resienten el desconocimiento y rechazo de la ortodoxia académica.

Rodrigo Soto presenta otro trabajo sobre el lugar del deporte y los deportistas en el gobierno de Sebastián Piñera. Luego de una breve historia del deporte en general, de la relación entre política y deporte y de las políticas deportivas en Chile, se pasa al análisis del discurso como herramienta para leer ciertas prácticas sociales. En particular, las relativas a la adopción por el Gobierno de Sebastián Piñera de un conjunto de propuestas para hacer de Chile "un país de deportistas". Se mira críticamente la construcción de un imaginario que, ya en el siglo XXI, vuelve sobre mensajes e imágenes del deporte muy semejantes a las de comienzos del siglo XX. Estas se afirman en dos direcciones: la de un conjunto de valores propicios para una juventud sana y una población activa; y la de un camino de triunfo en competencia propio de los deportistas de élite. Lo interesante es cómo a ello se dedica un esfuerzo consistente que parece contrastar con la inversión pública en la materia.

El capítulo 6 lo ocupa Argentina con un texto de Pablo Alabarces quien, de manera propiciatoria, examina comparativamente la invención de imágenes sociales a partir del tipo de fútbol practicado por Brasil y Argentina. Para ello, fija su acento en las diferencias entre europeísmos y tropicalismos futbolísticos, tema que permite, sin duda, una ardua discusión que puede convertirse en todo un clásico académico futbolero. Y lo hace en una interesante discusión con los trabajos previos de Simoni Guedes y los reconocimientos a Eduardo Archetti. Ah, y las citas procedentes 
a los textos de Roberto Fontanarrosa quien, con entrañable humor, construye las mejores imágenes de los nacionalismos futboleros de la región (y el mundo). Con un llamado final a la cordura, pues lo que parece haberse dado es un juego de espejos entre brasileños y argentinos que tiene hondura histórica, pero que sigue en permanente construcción, como pudo constatarse durante Brasil 2014.

Nicolás Cabrera introduce una mirada particular a la relación entre barras, identidad y violencia, reconstruyendo el quehacer de la hinchada de Belgrano de Córdoba y la transmutación de unas identidades mucho más políticas a unos imaginarios de violencia, aguante $y$ resistencia, pero en todo caso, atravesados por una dinámica social que apunta a la exclusión y a la conflictividad no tramitada. Hay en el texto muchas sugerencias para la enorme cantidad de investigaciones de caso sobre el barrismo. Entre ellas, la relativa a los "territorios peligrosos".

El capítulo 7, a la manera de Garrincha o de Jairzinho en 1970, le corresponde a la rica producción brasileña. En ella se incluye, primero, el trabajo de Simoni Lahud Guedes sobre "los 'europeos' del fútbol brasileño" o de cómo la llamada "patria de chuteiras" se enfrenta a la amenaza del mercado. Aunque es un texto que centra su preocupación en lo sucedido en el mundial de 1998, sin duda tiene un trasfondo analítico muy rico, razón por la cual el texto de Alabarces dialoga con este. Además del usual recuento histórico sobre la llegada del fútbol al país y su particular difusión popular, Guedes recupera la noción de juego en la línea de Huizinga y es desde allí desde donde propone la lectura específica del fútbol, del fútbol en Brasil y del hondo significado de las copas mundiales. Una preocupación central del texto está asociada a la tensión entre un modo brasileño de jugar al fútbol, manifiesto en sus principales figuras, y las modificaciones y desafíos a que este modo se enfrenta al enfrentar de manera protagónica la creciente internacionalización y mundialización del fútbol profesional. Como es obvio, esta tensión se pone de manifiesto en el desempeño del seleccionado brasileño en las distintas copas mundiales, pero especialmente en el artículo son tratadas la de 1998 y la de 2002: en una, con la derrota, en otra, con el triunfo, por lo cual los significados y los discursos que los medios y los hinchas han creado en torno a la conformación de selecciones de "extranjeros" que representan al Brasil tenderían a contradecirse. No obstante, dado que el artículo se escribe previo al mundial de 2002, lo que está más presente es cómo esa mundialización y mercantilización que se ha visto mediante los jugadores de fútbol parecería anticipar o acompañar procesos que están desbordando a la propia sociedad brasileña. $\mathrm{O}$, aún más, refleja la enorme tensión entre nación y mundo, entre sociedad nacional y globalización, entre soberanía y mercado.

Edison Gastaldo presta atención a lo que denomina "um jogo de identidades: Gaúchos, brasileiros e a imprensa esportiva na copa do mundo" (pág. 164). En particular hace seguimiento a la narrativa de diversos diarios en el previo, durante y después del mundial de 2002 en Corea-Japón. Más allá del triunfo que llevó al pentacampeonato de la selección brasileña, lo que resulta interesante en el ejercicio analítico es la constatación de una otra identidad del fútbol brasileño, que culmina con el triunfo de un modelo "gaúcho" de vivir y jugar al fútbol, pero que recoge tensiones centro-periferia, dentro de Brasil, de vieja data. Esta otra identidad toma fuerza en la figura del director técnico Felipe Scolari quien, previamente, ha logrado triunfar con el Gremio de Porto Alegre. Y, como lo constatan los autores, aunque el equipo en verdad no fuera necesariamente "gaúcho", tal fue la construcción imaginaria, compartida socialmente que, finalmente se impuso. El texto se deleita mostrando las tensiones, los entrecruzamientos, la evolución de esta otra identidad nacional futbolera, que en últimas lo que indica es la inexistencia de una sola identidad nacional brasilera y, más bien, un entramado de identidades regionales que se disputan la prevalencia y que, históricamente, imponen imágenes compartidas. 
Ronaldo Helal y Alvaro do Cabo vuelven sobre un tema que ocupa muchos de los análisis y las referencias: la disputa Brasil-Uruguay. Inevitablemente, esta confrontación está signada por lo sucedido en el Maracaná en 1950, aunque en el texto se examina lo sucedido en Guadalajara en 1970. Se hace una revisión de las narrativas de varios periodistas presentes en México 70 que, si bien exaltan la garra charrúa y reconocen las posibilidades de un nuevo milagro en cabeza de Uruguay, que podría revivir lo sucedido en 1950, son conscientes también del juego y la superioridad que en ese mundial demuestra el onceno brasileño. Por ello, aun con las quejas por la decisión arbitraria de cambiar la sede del juego, terminan por sumarse a los reconocimientos generales al tricampeón mundial comandado por el Rey Pelé. El texto hace un ejercicio interesante de reconstrucción de esas narrativas, del partido, de situaciones como la presencia de Ghiggia (anotador del segundo gol contra Brasil en 1950) en tierras brasileñas para la fecha en que se va a jugar el partido. Y, desde allí, indican posibles caminos para examinar asuntos de gran relevancia como la construcción de la derrota y la posible disolución de enemistades en la identificación con el mérito del rival. Aspectos en que se juega una reconfiguración simbólica en cortos períodos, a la vez que sin duda el fútbol hace presencia en la memoria colectiva de una nación.

Alvaro do Cabo aborda de manera directa el tema de la memoria y las representaciones colectivas en las copas del mundo, desde una perspectiva teórica. Apoyándose de manera importante en Le Goff hace un recorrido general por esta veta de análisis que encuentra en el fútbol un material enormemente llamativo para desarrollar la temática. De allí que, más que un estudio de caso específico, recorra con ejemplos varios y referencias diversas lo que se puede encontrar en la dinámica futbolera y de lo nacional en varios países de la región, especialmente Uruguay, Argentina y Brasil. Está presente, también, la referencia a las narrativas de la victoria y las de la derrota, así como la particular atención a cómo los medios van construyendo esta memoria colectiva específicamente en el devenir de las copas del mundo. Y deja la pregunta abierta acerca de si tales memorias corresponden a hechos sociales objetivados o son meros productos de las mesas redondas televisivas y los cuadernillos deportivos de los principales diarios.

Leila Salvini y Wanderley Marchi Júnior tratan una temática reciente, distinta, pero de gran relevancia, como es la del fútbol femenino en Brasil, desde la perspectiva de las estrategias para la legitimación de un habitus de mujeres en un espacio de dominación masculina. Siendo un tema de creciente importancia, luego de unas referencias históricas a una práctica que estuvo incluso prohibida por razones de salud y culturales, se enfocan en dos factores que consideran relevantes: los uniformes deportivos exclusivos para las mujeres y las tensiones entre habitus masculinos y femeninos desarrollados por las jugadoras. Para ahondar en la temática, desarrollan cuatro entrevistas a profundidad con jugadoras que han formado parte de la selección brasileña femenina de fútbol en épocas recientes. Cabe señalar que tanto la temática general como los abordajes particulares dejan una estela de posibilidades analíticas y de reflexión que resultan muy llamativas y que, en muchos aspectos, requieren de lecturas semejantes para el fútbol masculino.

Finalmente, Jessica Montanhini de Souza enfrenta el tema de la identidad nacional bajo el papel que juega el fútbol en ello y con una hipótesis: lo que está en juego, más que la identidad, es la propia noción de modernidad. De los trabajos presentados hasta aquí es el que hace una más cercana referencia a la Copa Mundial de Brasil 2014 y, por tanto, pone sobre la agenda del análisis un conjunto de temáticas que van desde el jogo bonito, pasando por la presencia de los "extranjeros" en la selección y el gran dilema de no lograr ganar en casa. A ello, se suma el sentido político y económico de la organización del Mundial y los Juegos Olímpicos, que es precisamente donde entra en tensión y reconfiguración el tema de un Brasil 
moderno o, más bien, de diversos brasiles en una modernidad que está siempre en construcción y permanente retroalimentación. Con lo sucedido en la Copa Confederaciones y el desencuentro como sociedad y como fútbol del Brasil 2014, es innegable que los planteamientos de Montanhini abren un espacio de inmediata atención para actualizar las reflexiones en curso.

El octavo capítulo le corresponde a Uruguay. Cristian Maneiro y Wanderley Marchi Júnior trabajan el caso uruguayo desde la perspectiva de quien arrancó siendo un gran ganador y ahora sufre intensamente para conseguir los mínimos resultados requeridos para ir a un mundial. La pregunta por la relación entre fútbol y nacionalismo está presente, pero si bien se hace un recorrido histórico breve, en realidad se sigue con detalle el desempeño de éxito y declive de la "celeste" en los últimos seis años. Ello les permite intentar responder dos cuestiones muy concretas y relevantes: "¿cómo se construyen los discursos mediáticos durante el período de auge y consolidación?" (pág. 215); es decir, el lapso que va de 2008 a 2011 y que incluye la eliminatoria al mundial de Sudáfrica 2010 y el triunfo en la Copa América 2011 en Argentina; $y^{\prime \prime}$ ¿qué explicaciones se ensayan para la etapa de decadencia actual y cómo se reacciona ante la misma?" (pág. 215), es decir, lo que corresponde a la eliminatoria a Brasil 2014. Como es obvio, surge también la inquietud por las narrativas de lo sucedido en este mundial y del insuceso de Luis Suárez contra el italiano Chiellini, pero esto no alcanzó a ser tratado en este texto. En todo caso, luego de la habitual revisión histórica y de apoyarse en clásicos de la sociología como Durkheim, Mead, Parsons para utilizar algunos de sus conceptos y enfoques para el análisis de lo social, examinan encuestas, videos, referencias periodísticas para señalar la significación del combinado patrio y sus figuras durante los triunfos, pero también cuando estos no se dan. Allí, esbozadas algunas características de lo sucedido y algunas hipótesis de trabajo, se cierra el texto.

Finalmente, el noveno capítulo está dedicado a Colombia. Bajo el mote del "toque-toque y de aquello nada". El primero es la reedición del texto de Andrés Dávila y Catalina Londoño publicado en el libro compilado por Pablo Alabarces, Futbologías: fútbol, identidad y violencia en América Latina (Buenos Aires, Clacso-ASDI, 2003), el cual fue una primera versión de la investigación sobre Selección Colombia e identidad nacional, que hizo parte del trabajo sobre "Íconos, ídolos y símbolos: tentativas en la construcción de la nación en Colombia". La segunda versión, resultado final de la investigación, fue publicada con el mismo título en Ingrid Bolívar, Germán Ferro y Andrés Dávila (coordinadores), Cuadernos de nación: belleza, fútbol y religiosidad popular (Bogotá, Ministerio de Cultura, 2001). El texto reeditado hace una primera aproximación conceptual e histórica al tema, pero por efectos del momento en que fue escrito, se centra en los orígenes del proceso que condujo a esa renovada significación del seleccionado colombiano en términos de la nación, lo cual se localiza en el período 1985-1987. En la versión definitiva, el recuento histórico en clave de selección y nación se completa hasta el año 2000 y, además, se hace un ejercicio de análisis del discurso, siguiendo la metodología de los actantes, en relación con los discursos de nación construidos en siete juegos de la selección Colombia, cuatro triunfos y tres derrotas. Se obtienen allí hallazgod muy interesantes en torno a la construcción paradójica de una imagen de lo nacional tanto en las mieles del triunfo, como en las hieles de la derrota.

A continuación, Beatriz Vélez trabaja el tema de la posible configuración de una identidad antropológica en el fútbol, bajo los conceptos del oikos y la matria. Con una singular sensibilidad por el juego del fútbol como representación, con un lugar muy especial para las corporalidades y la belleza, se adentra desde la antropología en la cuestión de las identidades, sean estas territoriales, comunitarias pero, sobre todo, producto de una interacción simbólica entre jugadores y espectadores. Pero como lo sugieren sus subtítulos, la identidad es un "collage" o, aún mejor, las identidades son nómadas. Lo cierto, en definitiva, es que "la identidad en devenir 
es fuente de resignificaciones y entonces de movimiento y de crecimiento hacia nuestra humanidad" (pág. 244). El fútbol, entonces, como identidad telúrica se halla en la poética del oikos y la matria; pero para explicarlo, y entenderlo, nada mejor que leer los hermosos párrafos de las páginas 246 y 247.

Stevens Ruiz Pérez da un salto a una temática cercana y hermana, pero que necesita de otras claves para su lectura. Se centra en el fenómeno del rugby en Sudáfrica y la forma como cambió el blanco y negro por el arco iris, asunto épicamente relatado en la película Invictus.

Eduardo de Souza Gómes nos ayuda a llenar los vacíos historiográficos, sociológicos, antropológicos y politológicos, al dar cuenta del papel del fútbol en la formación de la identidad nacional colombiana en el período 1948-1951, momento de profesionalización (ilegal) del fútbol en el país.

Alejandro Villanueva Bustos se adentra en la temática general pero desde la perspectiva del manejo que se está dando a las hinchadas. Es, en últimas, una mirada crítica a las normas y políticas que se han venido diseñando y elaborando en los últimos años en el país y que tienen, hasta el año 2012, un componente muy fuerte de estigmatización y condena, aunque hayan generado algunas dinámicas positivas. En esta tensión queda planteado el tema.

Guillermo Montoya, finalmente, cierra el capítulo con un recuento elaborado de los asuntos que son secreto, silencio o temas tabú en el fútbol colombiano. Para llegar a ellos, ha recorrido primero la mirada sobre lo visible, lo destacable, positivo o negativo. $\mathrm{Y}$ en tal sentido, hace un llamado de atención.

El breve epílogo corre por cuenta de Edgar Felipe Amaya Vega. Allí llama la atención sobre la extraña homogeneidad, por no decir emulación, de las hinchadas o barras de cada uno de los países, respecto del fenómeno original en Argentina. Tal mirada conduce a repensar los temas de identidad y nación en relación con el fútbol, dado que las barras como tal reproducen primero esquemas de diferenciación, separación, distinción de los rivales. Empero, de manera paradójica, lo hacen sobre un patrón común que se importa, sin aranceles culturales, de la Argentina.

Reseñado de manera sintética cada uno de los textos incluidos, pero con detalles que se esperan sean centrales, vale la pena hacer algunas anotaciones que, sin duda, apenas señalan unas primeras reflexiones ante la riqueza encontrada.

En primer lugar, se destaca el esfuerzo de compilar trabajos que conciernen a toda la región y, como es obvio, a los países que clasificaron al Mundial de Brasil 2014. Hay, en esto, una riqueza producto del origen de los trabajos y nada más.

En segundo lugar, el libro actualiza, recoge, propone las interpretaciones en curso desde las ciencias sociales. Como siempre, habrá excluidos o no conocidos, pero ello ya es un mérito. A futuro habrá que sacar un volumen con los que se quejen por no haber sido incluidos.

En tercer lugar, el libro deja una sensación a ratos contradictoria. Sin duda, es ya un campo de estudios que ha superado la fase gestacional. Se podría arriesgar, incluso, la idea de que en varios sentidos hay procesos de consolidación: en los abordajes sobre la nación, los nacionalismos, las identidades, las narrativas, los discursos, el fútbol, el papel del seleccionado, de los jugadores, los técnicos, los medios, la publicidad, los directivos, los gobiernos, la FIFA. En fin, el listado puede volverse interminable. Pero así como hay maduración y consolidación, el proceso no es homogéneo. Hay países con muchos más avances, mayor producción, innovaciones, reelaboraciones, hallazgos. Hay países con trabajos apenas en ciernes. Pero más preocupante, hay países que no aparecen todavía y que han jugado un papel futbolero significativo: Paraguay y Perú, por ejemplo. Y, resulta llamativo, que varios de los trabajos tienen que seguir una ruta primordial: desde 
la definición básica de conceptos y enfoques, pasando por el recuento del fútbol en general y en cada historia particular, hasta aterrizar en el asunto concreto que se va a trabajar.

Para terminar, hay una disyuntiva en ciernes. Si se revisan los trabajos, es factible clasificarlos entre aquellos que priorizan el fútbol y sus dinámicas, mientras otros hacen prevalecer lo social o lo político o lo económico. Las interrelaciones entre los fenómenos difícilmente logran equilibrios óptimos (al estilo Pareto). Y como lo señalaba Alabarces hace varios años, todavía la comparación no ha llegado. Y es el propio texto de Pablo el que constituye la excepción que confirma la regla. En cualquier caso, y como se sugiere a lo largo de la reseña, Brasil 2014 nos ha legado material para una segunda edición revisada, actualizada y aumentada. 
